\title{
Emotional Intelligence Among the Fourth Year Nursing Students: A cross-sectional study
}

\author{
Bander Albagawi \\ University of Hail, Saudi Arabia
}

\begin{abstract}
In an educational viewpoint, emotional intelligence(EI) continues to receive a substantial amount of attention as it assumes to prepare the students towards a better person in the workplace. The researchers' employed quantitative-correlational approach as it aims to determine the emotional intelligence among the male and female nursing students in the fourth year level, and its relationship to their demographic information. The researchers adapted the Arabic version of the Bar-On Emotional Quotient Inventory: short (EQ-I:s). There were 72 nursing students who actively participated in the study giving an $86 \%$ response rate. The results revealed that the level of emotional intelligence of the nursing students was high $(\mathrm{m}=3.97, \mathrm{SD}=$ 0.78), on the other hand, the result of the Pearson $r$ test indicates that there is no significant correlation between the fourth year nursing students' emotional intelligence level and student gender $(p=0.796, r=0.031)$, civil status $(p=0.497, r=$ $0.081)$, and age $(p=0.711, r=0.044)$. The stress management of the nursing students received the lowest, while age, gender, and civil status have no influence to their emotional intelligence. In order for the students to emotionally responsive to the critical events in their life, a tailored stress management program to meet the diverse needs of the students is highly recommended.
\end{abstract}

Keywords: Emotional Intelligence, Nursing students, Kingdom of Saudi Arabia

\section{INTRODUCTION}

In an educational viewpoint, emotional intelligence(EI) continues to receive a substantial amount of attention as it assumes to prepare the students towards a better person in the workplace. Accordingly, it is the key to professional success and an important predictor of health and work-related outcomes [1]. Emotional intelligence is the ability of the person to sense what is going on, to know how it feels while in that situation, to be able to assess and take into account other people's thoughts and feelings accurately and to respond appropriately [2]. To some, it is the ability to perceive accurately, appraise, express emotion, and the ability to use and/or generate feelings when they help thoughts; the ability to understand emotion and emotion knowledge; and the ability to regulate emotion to promote emotional and intellectual growth [3]. In the nursing field, emotional intelligence is considered an essential requirement in health care practice [4], as such, nurses need to have high levels of emotional intelligence skills to cope with the emotional demands of the healthcare environment. Emotional intelligence creates the ability to face inter-personal conflicts through handling emotional responses, being empathetic, and remaining sensitive to patient concerns which in turn increase proper teamwork to usefulness and better caregiving for the patient. Nurses also must emotional intelligence for recognizing and managing their own emotions not only for providing high-quality caregiving but also for maintaining their own health, feel valued, be satisfied, and motivated [5].

Existing evidence suggests that life success depends more on emotional intelligence than cognitive intelligence. Emotional intelligence leads to better output. Indeed, researchers like 
Delpasand et al. [6] claimed that emotional intelligence results in better teamwork, problemsolving ability, and reduction of stress. Accordingly, nurses who had higher emotional intelligence were more successful regarding patients and experience less burnout. As Barkhordari and Rostambeygi [7] put, there has been a direct relationship between emotional intelligence and positive performance including more appropriate teamwork, more effective organizational interactions, more solutions for conflicts, and lower levels of tension. On the other hand, Landa and López-Zafra [8] believed that emotional intelligence is positively associated with health and negatively with stress. In the same line, El-sayed [9] reported a negative relationship between emotional intelligence and occupational stress and self-efficacy. In a meta-analysis study conducted by Michelangelo [10], the author concluded that there is statistically significant evidence that EI training and education improves critical thinking skills of nursing students. Amraei [11] suggested that high emotional intelligence can lead to more successful management, job satisfaction, and organizational commitment. And expanding that nurse with a lower level of self - management is less accepting of patients' complaints and criticisms. In contrast with those with better self-management skills who are more accepting of others' views and demands.

Nurses with high emotional intelligence have a better self - awareness and as a result are more skilled in their interpersonal relationships. By having a better empathy, they show more interest in connecting with patients and responding to their emotional needs. That is where the role of emotional intelligence in having an efficient nurse-patient relationship demonstrates itself. In fact, the nurses who are more aware of emotions have a more respectful attitude in their interactions with patients and can manage patients better by knowing their emotions and needs. This skill is also known as one of the most important factors in improving cooperation among nurses themselves [12]. Stifter [13] mentioned that, emotional intelligence has five fields: 1) Recognition of emotions ( how confident somebody is in his own emotions, how determined he is when making decisions); 2) Treatment of emotions ( the skill which shows, how far we can influence our emotions and how far they can influence us): 3) Self-motivation ( target-oriented mobilization of emotions):4) Recognition the emotions of others: 5) Treatment of relations: influencing the emotions of others

While vast of the researches show the importance of emotional intelligence in enhancing nursing students' performance, this assumes that it translates to job performance and organizational commitment soon they will face the real world. As such, it is important to assessing emotional intelligence level among fourth-year nursing students before graduation and before entering to the practical life as an attempt to predicting the future success of the students in their work life. Also, assessing levels of EI among nursing students is essential for ensuring effective nursing education. Thus, this research aims to determine the level of emotional intelligence of the nursing students at the College of Nursing, University of Hail, Kingdom of Saudi Arabia. Specifically, to determine the emotional intelligence among the nursing students in the fourth year level, and its relationship to their demographic information.

\section{METHODS}

The researcher employed a quantitative- cross sectional design to represent the phenomenon of emotional intelligence of the fourth year nursing students and its relation to their demographic information. This research is conducted at the University of Hail, particularly at the College of Nursing where both the male and female students served as respondents. The researcher employed a convenience sampling resulted to $86.74 \%$ response rate.

The tool is a self-administered and it consists of two parts, part one is the demographic information sheet which includes data about age, sex, and marital status. The second part is the 
Arabic version of the Bar- On Emotional Quotient Inventory: short (EQ-I:s) which adopted from Ahmed et al. [14]. The Bar-On Emotional Quotient Inventory: Short (Bar-On EQ-i: S) is a shortened version of the Bar-On Emotional Quotient Inventory (Bar-On EQ-i; Bar-On). A selfreport measure designed to assess the core features of emotional intelligence, designed for individuals who are 16 years of age or more. The tool was translated to Arabic and modified by Ahmed et al. [14] to suit the Arabic culture, including 53 items grouped under five main domains and 15 subscales as follow:

1) Intrapersonal competencies: Includes 16 items (assess Competencies and Skills related to Self-awareness and self-expression) grouped under five subscales: selfesteem (4 items), self-awareness ( 4 items), assertiveness (3 items), independence (2 items), and self-actualization (3 items).

2) Interpersonal competencies: Includes 13 items (assess Competencies and Skills related to Social awareness and interpersonal relationship) grouped under three subscales: empathy (4 items), social responsibility(3 items), and personal relationships (6 items).

3) Adaptability: Includes 9 items (assess Competencies and Skills related to Change management) grouped under three subscales: reality testing (3 items), flexibility (3 items), and problem-solving (3 items).

4) Stress management: Includes 8 items(assess Competencies and Skills related to Emotional management and regulation) grouped under two subscales: stress tolerance (4 items), and impulse control (4 items).

5) The general mood: Includes 7 items (assess Competencies and Skills related to Selfmotivation) grouped under two subscales: optimism ( 3 items), and happiness ( 4 items)

The responses were scored on a five-point Likert scale rating from 1 (not true for me) to 5 (true for me). The higher the score the higher emotional intelligence level.

\section{Validity \& Reliability:}

The EQ-i: Short has been demonstrated to be a valid and reliable instrument. The EQ-I: s had acceptable alpha levels, ranging from 0.76 to 0.93 (Bar-On, 2002). While validity and reliability of the overall Arabic version of the EQ-I:s scale was reported by Mohamed et al. [15] to be .865. Also, the content validity of the tool was reported by Ahmed et al. [14]. The Cronbach's Alpha for the overall Arabic version of the EQ-I:s scale in this study was 0.908. indicating the high reliability of the scale.

A pilot study was carried out before starting data collection. It consisted of $10 \%$ of the study sample selected randomly to ensure the clarity, feasibility, and applicability of the tool and to estimate the time needed to fill in the tool's items. The time required to fill in the questionnaire ranged from 10-15 minutes. No modification was done. Data obtained from the pilot study was added to the study results.

\section{Ethical Consideration}

Approval to conduct the study was obtained from the Scientific Research Ethics Committee at the faculty of nursing, University of Hail. The participants were informed that their participation in the study is completely voluntary and there is no harm if they choose not to participate, and no individual information is shared outside of the researcher. The participants did not write their names in the questionnaire. Consent was established with the completion of the questionnaires. 


\section{Data processing and analysis}

Data cleanup and cross-checking were carried out before the analysis. Data analyses were performed using SPSS software, version 15.0. p-values less than 0.05 were considered statistically significant. Descriptive statistics were used to understand participants' demographic information. Pearson $r$ test was used to determine the relation between the study variables.

\section{RESULTS}

Table (1). Demographic characteristics of the study participants $(n=72)$

\begin{tabular}{lcc}
\hline Demographic Information & Frequency & Percentage \\
\hline Age & 43 & $60 \%$ \\
$21-23$ & 4 & $6 \%$ \\
$24-26$ & 9 & $13 \%$ \\
$27-29$ & 7 & $10 \%$ \\
$30-32$ & 7 & $10 \%$ \\
$33-35$ & 1 & $1 \%$ \\
$36-38$ & 1 & $1 \%$ \\
$39-41$ & & \\
Gender & 36 & $50 \%$ \\
Female & 36 & $50 \%$ \\
Male & & \\
Civil Status & 24 & $33 \%$ \\
Single & 48 & $67 \%$ \\
Married & & \\
\hline
\end{tabular}

From 83 students both males and females, 72 students actively participated in the study giving a response rate of $86.74 \%$. Table 1 shows that 72 fourth year nursing students in the convenience sample actively to participate in the study. This sample was composed of 36 male and 36 female respondents. In terms of age, 43 of the respondents, equivalent to $60 \%$ of them belonged to the 21 -23-year-old bracket. With respect to civil status, $48(67 \%)$ of the respondents were married while 24 (33\%) of them were single. 
Table 2. Emotional intelligence level of nursing students as to intrapersonal, interpersonal, adaptability, stress management, and general mood $(n=72)$

\begin{tabular}{|c|c|c|c|}
\hline \multicolumn{2}{|r|}{ Item } & Mean & STD \\
\hline \multicolumn{4}{|l|}{ Intrapersonal } \\
\hline- & Self-esteem & 4.23 & 0.75 \\
\hline- & Self-awareness & 4.08 & 0.821 \\
\hline- & Assertiveness & 4.02 & 0.88 \\
\hline- & Independence & 3.92 & 0.860 \\
\hline- & Self-actualization & 4.04 & 0.819 \\
\hline & & 4.06 & 0.83 \\
\hline \multicolumn{4}{|l|}{ Interpersonal } \\
\hline- & Empathy & 4.039 & 0.774 \\
\hline- & Social responsibility & 4.10 & 0.687 \\
\hline- & Interpersonal relation & 4.11 & 0.714 \\
\hline & & 4.09 & 0.73 \\
\hline \multicolumn{4}{|l|}{ Adaptability } \\
\hline- & Reality testing & 3.94 & 0.745 \\
\hline- & Flexibility & 3.85 & 0.838 \\
\hline- & Problem solving & 3.94 & 0.802 \\
\hline & & 3.91 & 0.80 \\
\hline \multicolumn{4}{|c|}{ Stress management } \\
\hline- & Stress tolerance & 3.76 & 0.763 \\
\hline- & Impulse control & 3.59 & 0.887 \\
\hline & & 3.68 & 0.82 \\
\hline \multicolumn{4}{|c|}{ General mood } \\
\hline- & Optimism & 3.93 & 0.762 \\
\hline- & happiness & 4.01 & 0.607 \\
\hline & & 3.97 & 0.68 \\
\hline \multicolumn{2}{|c|}{ Overall Values of Emotional Intelligence } & 3.97 & 0.78 \\
\hline
\end{tabular}

Table 2 shows the emotional intelligence level among the fourth year nursing students. The level of emotional intelligence of the study respondents was highest for the interpersonal and intrapersonal competencies subscales $(\mathrm{m}=4.09, \mathrm{SD}=0.73 \& \mathrm{~m}=4.06, \mathrm{SD}=0.83)$ respectively), and lowest for the stress management subscale $(\mathrm{m}=3.68, \mathrm{SD}=0.82)$. Overall, it was revealed that the level of emotional intelligence of the nursing students was high $(\mathrm{m}=$ $3.97, \mathrm{SD}=0.78$ )

Table 3. Correlation Analysis between emotional intelligence level and students demographic information

\begin{tabular}{lcc} 
& $(\mathbf{n = 7 2})$ & \\
\hline Profile Variables & Computed $\mathbf{~}$ & P Value \\
\hline Sex & 0.031 & 0.796 \\
Social status & 0.081 & 0.497 \\
Age & 0.064 & 0.594 \\
\hline
\end{tabular}

Table 3 shows the correlation between emotional intelligence level and students demographic information. The result of the Pearson $r$ test indicates that there is no significant correlation 
between the fourth year nursing students' emotional intelligence level and student gender $(\mathrm{p}=$ $0.796, r=0.031)$, type $(p=0.270, r=0.132)$, social status $(p=0.497, r=0.081)$, age $(p=$ $0.711, r=0.044)$. or years of experience $(p=0.475, r=0.085)$.

\section{DISCUSSION}

The results of the current study revealed that the overall level of emotional intelligence of the nursing students was high. It is assumed that nursing students in this study can function effectively in meeting daily demands and challenges in their practical life. This result may be due to using of effective teaching strategies that enhance emotional intelligence competencies among nursing students during their academic education and to the clinical teaching effectiveness. This explanation was supported by Allen et al. [16]who study the relationship between emotional intelligence and clinical teaching effectiveness in nursing faculty in Canada and found statistically significant and moderately high correlation between emotional intelligence and clinical teaching effectiveness and concluded that a higher level of EI functioning was associated with a higher level of clinical teaching effectiveness. The present result agrees with Ibrahim et al. [17] who conducted a study in Egypt to assess Emotional intelligence and internet addiction among nursing interns and investigate the relationship between both. The findings showed that the majority of study subjects have high scores in EI in general. While, this result disagree with Mahmoud [18] who examined Emotional Intelligence among Baccalaureate Students at the Faculty of Nursing, Alexandria University, Egypt and reported that the majority of the studied students in the second, fourth, sixth and eighth semesters had moderate levels of the total score of emotional intelligence $(90.0 \%, 86.4 \%$, $87.6 \%$ and $92.4 \%$ respectively), In the same direction, Benson et al. [19] found that the majority of undergraduate nursing students across the four years had average/moderate emotional intelligence. However, important differences were found between findings of Suliman [20] who study the relationship between learning styles, emotional social intelligence, and academic success of nursing students enrolled in conventional and accelerated nursing education programs at Saudi Arabia. The author reported that most (66\%) of conventional program students scored close to the lower limit of the normal range (88) of the emotional intelligence score, and $75 \%$ of accelerated program students scored even lower (84). This result disagrees also with Vahidi et al . [21] who study the relationship between emotional intelligence and perception of job performance among nurses in North West of Iran. The finding of that study revealed that the mean score of nurses' emotional intelligence was weak.

The level of emotional intelligence of the study respondents was highest for the interpersonal and intrapersonal competencies subscales. The high score in the interpersonal competencies subscale indicates that the nursing students in this study have the ability to understand how others feel, able to cooperate and to establish a mutual relationship with others. While, the high score in the intrapersonal competencies subscale among students indicates that they have the ability to accurately perceive, understand, and accept oneself, able to understand and express one's emotions, and can strive to achieve their personal goals. This result agrees with Mohamed et al. [15] who examined the relationship between emotional intelligence and organizational stress among intensive care nurses at Zagazig University Hospitals and found that interpersonal domain had the highest percent mean score among others emotional intelligence subdomains (55.0\%). Followed by stress management and general mood sub scales (49.3\% and $49.2 \%$ respectively). This result agrees also with Cavins [22], who study the relationship between emotional intelligence and leadership practices among college students' leaders in the United States, and found that the intrapersonal component of emotional intelligence was demonstrated the highest score. While, this result disagrees with Abd El-Fattah et al. [23] who study the relationship between emotional intelligence and clinical teaching effectiveness among clinical teaching staff in the Faculty of Nursing - 
Beni Suif University. The result showed that the highest percentages $(74.5 \%, 70.9 \%)$ were high respectively for adaptability and general mood domains.

Meanwhile, the low score of the stress management competencies subscale indicates that the nursing students in this study cannot work well under pressure, can lose they control easily, and cannot manage their emotions. This may be due to lack of training courses for nursing students about stress management and how to deal with stressful situations. This result goes in the same line with those of a study conducted in Egypt, by Ahmed et al. [14], who introduce an intervention program for nursing students about emotional-social intelligence and leadership practices and founded that general mood and stress management were the lowest mean scores among nursing students. This result agrees also with Abd El-Fattah et al. [23] who reported that the lowest mean \pm Std. Deviation $(18.9350 \pm 4.81463)$ was stress management domain.

The findings of the present study revealed that there was no statistically significant difference in the emotional intelligence level between the fourth year male and female nursing students. It is most likely attributable to participants' homogenous backgrounds. Both groups have the same cultures and the same curriculum. This result agrees with Birks [24] who study Emotional intelligence and perceived stress in healthcare students. The results revealed no significant differences were found between males and females nor among professional groups for the EI measure. While disagreeing with Mahmoud et al. [18] who reported that male students had higher emotionally intelligence skills than females and an increased mean score of managing emotions than female students with a statistically significant difference was noted between them.

The results of the current study indicate that there is no significant correlation between the fourth year nursing students' emotional intelligence level against age, gender, and social status. This result agrees with Mohamed et al. [15] who indicates that there was no statistically significant relation in relation to total emotional intelligence mean score and the study participants age, gender, educational qualification, and years of experience. Also, this result agrees with a study done in Isfahan by Yamani et al. [25] who conducted a study to assess the relationship between emotional intelligence and job stress in the faculty of medicine and founded that there was no significant relationship between emotional intelligence and gender and work experience. While disagreeing with Mehta [26], who conducted a study about how emotional intelligence reduces occupational stress among teachers and clarified emotional intelligence increase with age and maturity.

\section{CONCLUSION}

The stress management of the nursing students received the lowest, while age, gender, and civil status have no influence to their emotional intelligence. In order for the students to emotionally responsive to the critical events in their life, a tailored stress management program to meet the diverse needs of the students is highly recommended.

\section{COMPETING INTERESTS}

The author declares no conflict of interest in this study

\section{References}

Beauvais AM, Brady N, O'Shea ER, Griffin MT.(2011). Emotional intelligence and nursing performance among nursing students. Nurse Educ Today. May;31(4):396-401. doi: 10.1016/j.nedt.2010.07.

Segal, J. (2013): Emotional intelligence (EQ), key skills for raising emotional intelligence. Available at: http://www.helpguide.org/mental/eq5_raising_emotional_intelligence.htmz Retrieved at 5/9/2014. 
Wong, C., Law, K. (2002). The effects of leader and follower emotional intelligence on performance and attitude: An exploratory study. The Leadership Quarterly, 13(3):243-274.

Yosefi, F. \& Safari, H. (2010): The relationship between emotional intelligence and the dimensions of quality of life, Psychological Studies, 5(4), 2-20.

Barriball, L., Fitzpatrick, J. \& Roberts, J. (2011): Emotional intelligence: Its relationship to stress, coping, wellbeing and professional performance in nursing. Nurse Education Today. 2(3), 226-340.

Delpasand, M., Nasiripour, A.A.,Raiesi, P. \& Shahabi, M. (2011): Relationship between emotional intelligence and occupational burnout among nurses in Critical Care Units, JCrit Care Nurs, 4 (2),79-86.

Barkhordari M, Rostambeygi P. (2013). Emotional intelligence in nursing students. J. Adv Med \&Prof;1(2):46-50.

Landa J M A \&, López-Zafra E. (2010). The Impact of Emotional Intelligence on Nursing: An Overview. Psychology, 1: $50-58$.

El-Sayed SH \& El -Zeiny H H A., \& Adeyemo (2014). Relationship between occupational stress, emotional intelligence, and self-efficacy among faculty members in faculty of nursing Zagazig University, Egypt. Journal of Nursing Education and Practice, Vol. 4 (4), 183-194.

Michelangelo L. (2015 Apr-June). The overall impact of emotional intelligence on nursing students and nursing. Asia-Pacific Journal of Oncology Nursing. Vol 2 ( 2 ), 118-124.

Amraei, M. (2011): The Relationship between Emotional Intelligence and Communication Skills of Librarians in Isfahan University and Isfahan University of Medical Sciences, Health Information Management, 8(5):662-72.

Saeid, Y., Javadi, m. \& Sirati Nir, M. (2013): On the relationship between emotional intelligence and demographical variables in nurses, Journal of Military Medicine, 15(1), 87-92.

Stifter, V. (2013): The role of emotional intelligence in knowledge sharing, Reprodukce lidského kapitálu vzájemné vazby a souvislosti. 9 - 10 .

Ahmed Z N A., El-Sayed N M., El-Sayed S H. (2014). Intervention Program for Nursing Students about EmotionalSocial Intelligence and Leadership Practices. Unpublished PhD thesis. Faculty of Nursing. Zagazig University, Egypt.

Mohamed S S G, El-Hosany W A., Hussein F M. (2015). Relationship Between Emotional Intelligence and Organizational Stress Among Intensive care Nurses at Zagazig University Hospitals. Unpublished Master Thesis. Faculty of Nursing, Zagazig University Egypt

Allen, D., Ploeg, J., Kaasalainen, S.(2012). The Relationship Between Emotional Intelligence and Clinical Teaching Effectiveness in Nursing Faculty. Journal of Professional Nursing, Volume 28, Issue 4, Pages 231-240

Ibrahim AF, Akel DT, Abd- El Fatah LAM, Abudari MO. (2016). Emotional intelligenceand internet addiction among nursing interns. Clinical Nursing Studies, Vol. 4(1), 70-80.

Mahmoud H M, Abd El-Dayem S M, Mousa M A. (2013). Emotional Intelligence among Baccalaureate Students at the Faculty of Nursing, Alexandria University, Egypt: Journal of Education and Practice. Vol.4(27), 49-61

Benson, G., Ploeg, J. \& Brown, B. (2010). A cross-sectional study of emotional intelligence in baccalaureate nursing students. Nurse Education Today, 30(1), 49-53.

Suliman W A. (2010). The Relationship Between Learning Styles, Emotional Social Intelligence, and Academic Success of Undergraduate Nursing Students. Journal of Nursing Research. 18 (2), 136-143

Vahidi M., Areshtanab H N. , \& Bostanabad M A. (2016). The Relationship between Emotional Intelligence and Perception of Job Performance among Nurses in North West of Iran. Hindawi Publishing Corporation Scientifica. Available from www.hindawi.com/journal. at 24/7/2016, 11 Am

Cavins, B.J.(2005):The relationship between emotional social intelligence and leadership practices among college student leaders. Published Ph.D, Thesis.

Abd El-Fattah, A M A., Wafik, W., Metwally, F G., \& Guindy, H A. (2015). The Relationship between Emotional Intelligence and Clinical Teaching Effectiveness among clinical Teaching Staff in Faculty of Nursing -Beni Suif University. Unpublished Master Thesis. Faculty of Nursing. Zagazig University, Egypt.

Birks Y., McKendree J., Watt I.(2009). Emotional intelligence and perceived stress in healthcare students: a multiinstitutional, multi-professional survey BMC Medical Education, 9:61.

Yamani, N., Shahabi, M. \& Haghani, F. (2014): The relationship between emotional intelligence and job stress in the faculty of medicine in Isfahan University of medical sciences, J Ady Med prof, 2(1), 20-26. 
Mehta, A. (2011) : A study of how emotional intelligence reduces occupational stress among teachers, International Monthly Refereed Journal of Research in Management and Technology, 11, 19-28. 